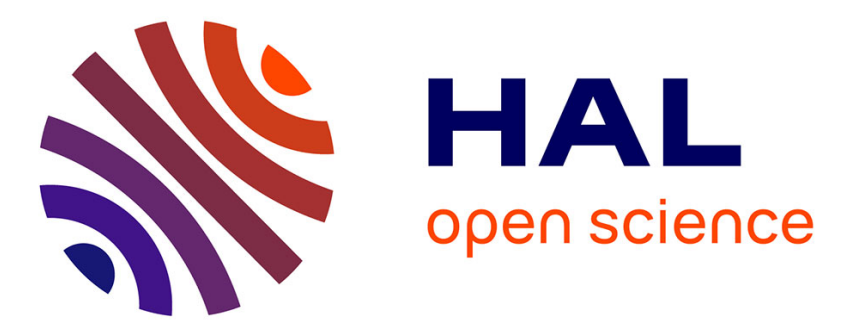

\title{
Photoactive Polyoxometalate/DASA Covalent Hybrids for Photopolymerization in the Visible Range
}

Amandine Boulmier, Mohamed Haouas, Somia Tomane, Laurent Michely, Anne Dolbecq, Anne Vallée, Vlasta Brezova, Davy-louis Versace, Pierre Mialane, Olivier Oms

\section{To cite this version:}

Amandine Boulmier, Mohamed Haouas, Somia Tomane, Laurent Michely, Anne Dolbecq, et al.. Photoactive Polyoxometalate/DASA Covalent Hybrids for Photopolymerization in the Visible Range. Chemistry - A European Journal, 2019, 10.1002/chem.201902573 . hal-02335765

\section{HAL Id: hal-02335765 https://hal.science/hal-02335765}

Submitted on 22 Sep 2020

HAL is a multi-disciplinary open access archive for the deposit and dissemination of scientific research documents, whether they are published or not. The documents may come from teaching and research institutions in France or abroad, or from public or private research centers.
L'archive ouverte pluridisciplinaire HAL, est destinée au dépôt et à la diffusion de documents scientifiques de niveau recherche, publiés ou non, émanant des établissements d'enseignement et de recherche français ou étrangers, des laboratoires publics ou privés. 


\title{
Photoactive Polyoxometalate/DASA covalent hybrids for photopolymerization in the visible range
}

\author{
Amandine Boulmier, ${ }^{[a]}$ Mohamed Haouas, ${ }^{[a]}$ Somia Tomane, ${ }^{[a]}$ Laurent Michely, ${ }^{[b]}$ Anne Dolbecq, ${ }^{[a]}$ \\ Anne Vallée, ${ }^{[a]}$ Vlasta Brezova, ${ }^{[c]}$ Davy-Louis Versace, ${ }^{*},[b]$ Pierre Mialane ${ }^{[a]}$ and Olivier Oms ${ }^{*},[a]$
}

\begin{abstract}
The synthesis of TBA-DASA-POM-DASA, the first photoactive covalent hybrid polyoxometalate (POM) incorporating a Donor-Acceptor Stenhouse Adduct (DASA) reverse photochrome, is presented. It has been evidenced that in solution the equilibrium between the colorless cyclopentenone and the highly colored triene conformers is strongly dependent not only on the nature of the solvent but also the countercations, allowing to tune its optical properties. This complex has been further associated to photochromic spironaphtoxazine cations, resulting in a material which can be activated by two distinct optical stimuli. Moreover, TBA-DASA-POMDASA, when combined with $\mathrm{N}$-methyldiethanolamine, constitutes a performing photoinitiating system for polyethylene glycol diacrylate polymerization and this under visible light irradiation, a promising result in a domain scarcely developed in POM chemistry.
\end{abstract}

\section{Introduction}

Until recently, most of the organic photochromic compounds reported in the literature were derived from various classes of molecules, mainly spiropyrans, ${ }^{[1]}$ diarylethenes, ${ }^{[2]}$ fulgides ${ }^{[3]}$ and azobenzenes. ${ }^{[4]}$ These systems, which can be activated by UV light, are of great interest due to their implication in numerous fields such as optical sensors, ${ }^{[5]}$ data storage ${ }^{[6]}$ or molecular logic gates. $^{[7]}$ However, in order to avoid high energy UV-light irradiation, efforts have been focused on the elaboration of reverse photochromes, i.e., which can be activated under visible light, as indigos ${ }^{[8]}$ or appropriately functionalized azobenzenes..$^{[4 b]}$ Actually, the less energetic visible-light irradiation is safer as it reduces the photodegradation of the system, thus is suitable for potential

[a] Dr. A. Boulmier, S. Tomane, Dr. A. Dolbecq, Dr. M. Haouas, Dr. A. Vallée, Prof. P. Mialane, and Dr. O. Oms Institut Lavoisier de Versailles, UMR 8180, Université Paris-Saclay, Université de Versailles Saint-Quentin en Yvelines 45 Avenue des Etats-Unis, 78035 Versailles cedex, France olivier.oms@uvsq.fr

[b] L. Michely, Dr. D.-L. Versace

Institut de Chimie et des Matériaux Paris-Est (ICMPE), CNRS-UPEC UMR 7182, 2-8 rue Henri Dunant 94320 Thiais, France versace@icmpe.cnrs.fr

[c] Prof. V. Brezová

Institute of Physical Chemistry and Chemical Physics, Faculty of Chemical and Food Technology, Slovak University of Technology in Bratislava, Radlinského 9,

SK-812 37 Bratislava, Slovak Republic

Supporting information for this article is given via a link at the end of the document.

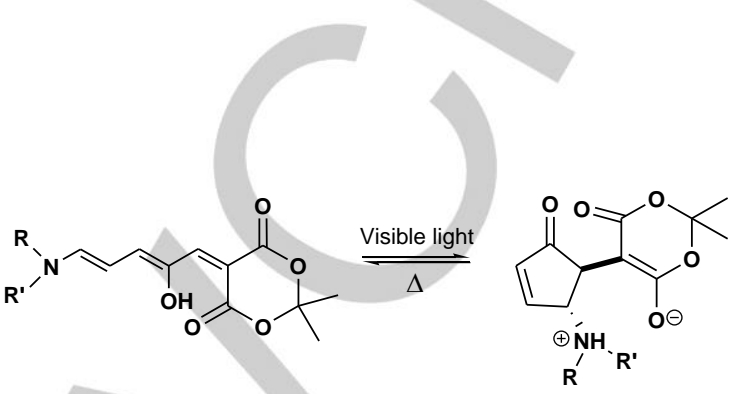

$$
\begin{array}{cc}
\text { Triene isomer } & \text { Cyclopentenone isomer } \\
\text { hydrophobic, colored } & \text { hydrophilic, colorless }
\end{array}
$$

Figure 1. Isomerization of DASAs (obtained from Meldrum's acid)

medical applications. ${ }^{[9]}$ Reported in 2014 by Read de Alaniz, the reverse photochromic family of Donor-Acceptor Stenhouse Adducts (DASAs) offers many advantages. ${ }^{[10 a, b]}$ In this new class of easy to synthesize T-type negative photochromes, the highly colored hydrophobic triene form switches to the colorless hydrophilic cyclopentenone isomer under visible-light irradiation. This last form is thermally unstable and reverts to the triene one under heating (Figure 1). The extensive work on this new class of photochromes during the five last years has been recently reviewed by Feringa et al... ${ }^{[10 c]}$ While the synthesis of a rich variety of pure organic compounds often incorporated into organic polymers has been largely developed, their interaction with inorganic materials has been scarcely reported. This aspect is nevertheless illustrated by the grafting of DASA entities onto magnetite nanoparticles by Klajn et al... ${ }^{[10 \mathrm{~d}]}$

Since 2010, some of us have developed an original class of solid state photochromic products based on the close association between polyoxometalates (POMs), which can be described as soluble molecular oxides of early transition metals $(\mathrm{V}, \mathrm{W}, \mathrm{Mo})$ in high oxidation state, ${ }^{[11]}$ and spiropyran (SP) derivatives. We can also note that recently, following this approach, a photochromic POM hybrid involving a diarylethene fragment has also been reported. ${ }^{[12]}$ Interestingly, to our knowledge, this assembly represents the unique example of POM-based system which can be switched between two forms exclusively on irradiation with visible light. So, on one hand, ionic assemblies were successfully isolated starting from spiropyran or spironaphtoxazines (SN) cations and a great variety of polyanions. ${ }^{[13]}$ Furthermore, covalent hybrid POMs were also synthesized via a coupling reaction between Anderson-type polyoxomolybdates or polyoxotungstates and photochromic molecules. ${ }^{[14]}$ Importantly, all these works have unambiguously demonstrated the crucial role of the inorganic platform. Indeed, whereas pure organic spiropyran compounds exhibit a strong photochromism in solution, they are usually poorly photochromic in the solid-state at room temperature. By the way, Harada et al. pointed out that the photochromism in such conditions is mostly prevented by the high 
rate of the thermal back reaction but enhanced by lowering the temperature what leads to a better stabilization of the merocyanine isomer. ${ }^{[15]}$ Thus, when associated to POMs, the resulting assemblies photoswitch in ambient conditions, even under low-intensity UV-irradiation (6 W). The kinetics of coloration and bleaching processes can be tuned by the nature of the POM and of the spiro derivative. Importantly, it has been possible to elaborate both a biphotochromic hybrid POM via the grafting of one SP and one SN group onto the same Mn-Anderson type $\mathrm{POM}^{[14 \mathrm{c}]}$ and a molecular fluorescent photoswitch associating BODIPY and SP entities, covalently linked to the inorganic platform. ${ }^{[14 d]}$ Following the idea to design multifunctional optical POM-based materials, herein is reported for the first time the synthesis and the characterization of a covalent POM/reverse photochromic

hybrid, (TBA) ${ }_{3}\left[\mathrm{MnMo}_{6} \mathrm{O}_{18}\left\{\left(\mathrm{OCH}_{2}\right)_{3} \mathrm{CNHCO}\left(\mathrm{C}_{16} \mathrm{H}_{22} \mathrm{O}_{5} \mathrm{~N}\right)\right\}_{2}\right] \quad$ (TBA: tetrabutylammonium) TBA-DASA-POM-DASA complex. NMR spectroscopy made it possible to fully distinguish and quantify the isomers ratio in solution. A great benefit of anionic hybrid POM is that new properties can be added via the introduction of suitable cations. Thus, the influence of the countercations $\left(\mathrm{TBA}^{+}, \mathrm{Na}^{+}\right.$or $\mathrm{SN}^{+}$) on the optical properties has been shown. Finally, and importantly, we demonstrated that the exceptional absorbance properties of the reported hybrid POM in the visible domain render it suitable as a photoinitiating system under visible light irradiation for POM-involved polymerization processes. Such obtained polymers also exhibit enhanced mechanical properties.

\section{Results and Discussion}

Synthesis and characterization of TBA-DASA-POM-DASA The rather simple synthetic pathway of the DASAs constitutes a great benefit. The first step consists in the activation of furfural with Meldrum's acid. Thus, the activated furan reacts with secondary amines in the second and final step. Besides, great efforts have been made these last years in order to develop new synthetic strategies leading to the formation of POM clusters functionalized by various organic fragments. ${ }^{[16]}$ Noticeably, ParacVogt et al. recently reported on a versatile postfunctionalization method allowing the grafting of amines, carboxylates and thiolates onto an Anderson-type POM platform, starting from the symmetrical chloro-functionalized $(\mathrm{TBA})_{3}\left[\mathrm{MnMo}_{6} \mathrm{O}_{18}\left\{\left(\mathrm{OCH}_{2}\right)_{3} \mathrm{CNHCO}\left(\mathrm{CH}_{2} \mathrm{Cl}\right)\right\}_{2}\right]$ entity. ${ }^{[16 a]}$ In order to combine POM and DASA chemistries, the coupling of this precursor with 1-butylamine (Figure 2) was performed in presence of tetrabutylammonium iodide and sodium carbonate. The targeted

product (TBA $)_{3}\left[\mathrm{MnMo}_{6} \mathrm{O}_{18}\left\{\left(\mathrm{OCH}_{2}\right)_{3} \mathrm{CNHCOCH}_{2} \mathrm{NHC}_{4} \mathrm{H}_{9}\right\}_{2}\right]$ which contains secondary amine groups was isolated as an orange powder. The ${ }^{1} \mathrm{H}$ NMR spectrum clearly shows the shift of the protons linked to the a carbon of the CO group from $4.19 \mathrm{ppm}$ in the chloro precursor to $3.41 \mathrm{ppm}$ in the final product (Figures S1-S2). This displays the complete substitution of the chloride atom for the nucleophilic butylamine. Integrations confirm the ratio between the TBA cations and the butylamine substituent. This new hybrid
POM was also characterized by ${ }^{13} \mathrm{C}$ NMR spectroscopy (Figure S3), IR spectroscopy (Figure S4) and

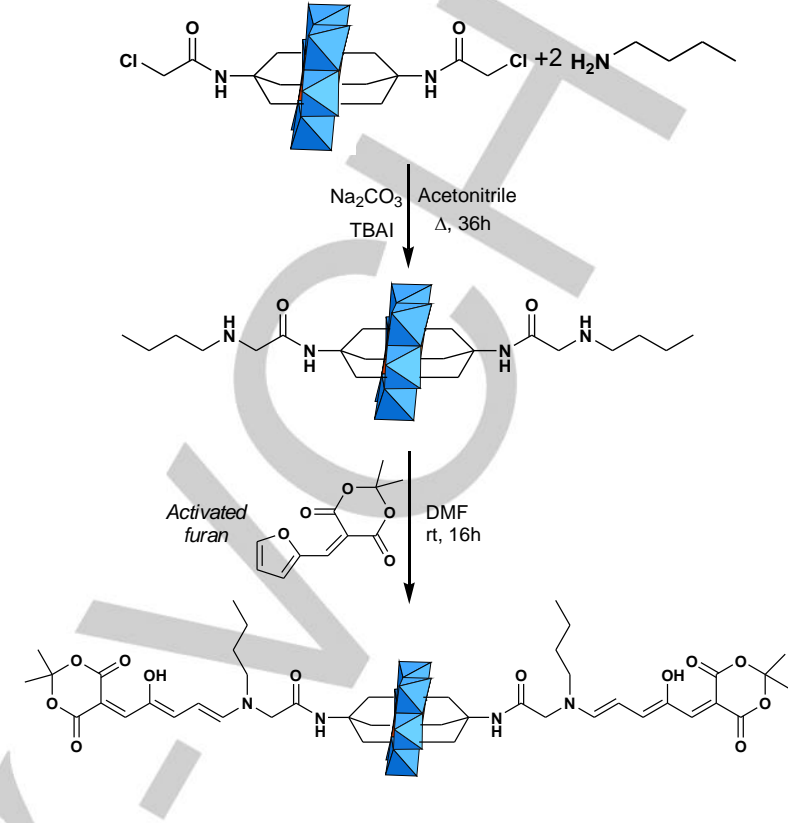

Figure 2. Synthetic pathway leading to TBA-DASA-POM-DASA (tetrabutylammonium cations have been omitted). The overall charge of the hybrid Anderson-type POM is 3- at each step.

elemental analyses (see Experimental section). TBA-DASAPOM-DASA was finally obtained in high yield by reacting (TBA $)_{3}\left[\mathrm{MnMo}_{6} \mathrm{O}_{18}\left\{\left(\mathrm{OCH}_{2}\right)_{3} \mathrm{CNHCOCH}_{2} \mathrm{NHC}_{4} \mathrm{H}_{9}\right\}_{2}\right]$ with an excess of activated furan in DMF at room temperature. We can note that the initial orange solution instantaneously turns dark red after the addition of few drops of the yellow furan solution, evidencing the formation of the POM/DASA adduct. The TBA-DASA-POMDASA hybrid was isolated after precipitation with a large volume of ether and the excess of the activated furan was discarded after two additional dissolution/precipitation cycles. Despite numerous crystallization experiments, single crystals of TBA-DASA-POMDASA suitable for $X$-Ray diffraction have still not been obtained. However, the hybrid has been thoroughly characterized using extensive techniques. ESI/MS (Electrospray Ionization Mass Spectrometry) in negative ion mode evidences envelopes related to monoanionic $\left([\mathrm{P}+2 \mathrm{TBA}]^{-}\right.$at $\mathrm{m} / \mathrm{z}=2310.95$, $\mathrm{P}$ referring to $\left.\left[\mathrm{MnMo}_{6} \mathrm{O}_{18}\left\{\left(\mathrm{OCH}_{2}\right)_{3} \mathrm{CNHCO}\left(\mathrm{C}_{16} \mathrm{H}_{22} \mathrm{O}_{5} \mathrm{~N}\right)\right\}_{2}\right]^{3-}\right), \quad$ dianionic $\left([\mathrm{P}+\mathrm{TBA}]^{2-}\right.$ at $\left.\mathrm{m} / \mathrm{z}=1034.47\right)$ and trianionic adducts $\left([\mathrm{P}]^{3-}\right.$ at $\mathrm{m} / \mathrm{z}$ $=608.90$ ) (Figure S5). In the infrared spectrum, three new intense bands appear compared to the secondary amine functionalized POM precursor (Figure S6). These signals at $1606 \quad(\mathrm{C}=\mathrm{C}$ stretching band of the conjugated olefinic group), 1347 (C-O and $\mathrm{C}-\mathrm{H}$ deformation bands) and $1137 \mathrm{~cm}^{-1}$ (C-O stretching band) clearly identify the triene part. ${ }^{[17]}$ The UV-Visible spectrum of TBADASA-POM-DASA in acetonitrile exhibits a $\lambda_{\max }$ centered at 532 $\mathrm{nm}$ (Figure S7). However, in the absence of light, the time dependent evolution of $A_{532}$ shows a decrease during $3 \mathrm{~h}$ until a plateau is observed (Figure S7), indicating that the room temperature equilibrium between the highly colored triene and the colorless cyclopentenone isomers is reached. The ${ }^{1} \mathrm{H}$ NMR 
spectrum of a $4 \mathrm{~h}$ aged acetonitrile solution of TBA-DASA-POMDASA evidenced the presence of the two forms
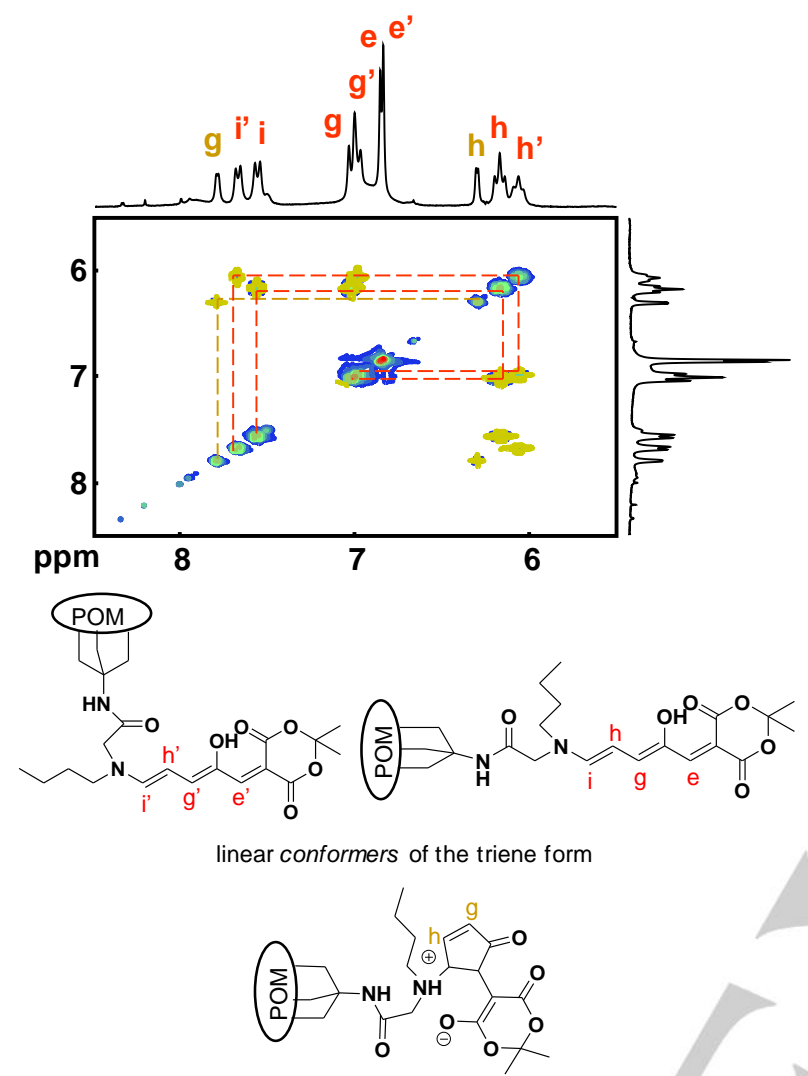

Cyclopentenone isomer

Figure 3. Top: part of the ${ }^{1} \mathrm{H}-{ }^{1} \mathrm{H}$ COSY NMR spectrum (5-9 ppm) of TBADASA-POM-DASA; bottom: representations of the conformers of the triene form and of the cyclopentenone form of TBA-DASA-POM-DASA.

(Figure S8). While the signals in the $0-5 \mathrm{ppm}$ range are rather difficult to interpret accurately as they are assigned to the numerous protons of the TBA cations, butylamine groups and methyl groups of the Meldrum's acid, the 6-12 ppm domain provides essential information. Furthermore, it covers the peaks related to the triene form, including the $-\mathrm{OH}$ function (at 11.38 $\mathrm{ppm}$ ) along with two doublet signals belonging to the cyclopentenone form. As mentioned by Beves et al., ${ }^{[18]}$ the colored linear DASA isomer presents two conformers due to the restricted $\mathrm{C}-\mathrm{N}$ bond rotation which possesses a substantial double bond character. An increase of the temperature to $80^{\circ} \mathrm{C}$ led to the coalescence of the two sets of signals of the conformers whereas the peaks of the colorless isomer are unchanged (Figure S9). By means of NMR studies (including ${ }^{13} \mathrm{C},{ }^{1} \mathrm{H}-{ }^{1} \mathrm{H}$ COSY and NOESY, and ${ }^{1} \mathrm{H}-{ }^{13} \mathrm{C}$ HSQC and HMBC experiments), the complete assignment in this region was unambiguously performed (Figure 3 and Figures S8-S22). Importantly, this investigation reveals the predominance of the triene form (78\%) over the cyclopentenone isomer (22\%). UV-Visible spectroscopy investigations from four experiments with distinct concentrations $\left(10^{-4}, 10^{-5}, 510^{-5}\right.$ and $\left.10^{-6} \mathrm{M}\right)$ indicate that the ratio between the two isomers is not concentration dependent, in accordance with the works of Beves. ${ }^{[18]}$ Thus, by extrapolation with the ${ }^{1} \mathrm{H}$ NMR experiments (performed with higher concentration solutions), the molar absorption coefficient of the TBA-DASA-POM-DASA under the triene form is estimated at $2 \times 10^{5} \mathrm{M}^{-1} . \mathrm{cm}^{-1}$ (Figure S23).

\section{Photoactivity of TBA-DASA-POM-DASA}

The bleaching of the system was then explored with a commercial photochemical flow reactor providing a continuous monochromatic irradiation at $\lambda=525 \mathrm{~nm}$. This method leads to a substantial bleaching after one hour (the loss of intensity of $\mathrm{A}_{532}$ is around $68 \%$, Figure S24). Unfortunately, once fully discolored, the thermal backisomerisation (from the cyclopentenone form to the triene isomer) is not observed even after prolonged heating of the colorless acetonitrile solution. This is also observed when the experiment is performed in DMF. In the literature, the reversibility of the switching process for DASA compounds is a key point as it is strongly influenced by the solvent and the nature of the donor group. In our case, in contrast with pure organic derivatives obtained from alkylamines that essentially exist in the triene form, the initial presence of the two isomers for TBA-DASA-POM-DASA is indicative of their close energies similarly to arylamine-based organic DASAs, ${ }^{[18]}$ suggesting, at first glance a reversible photoswitch. However, as for the yet reported grafting of DASA molecules onto $\mathrm{Fe}_{3} \mathrm{O}_{4}$ nanoparticles, ${ }^{[10 \mathrm{~d}]}$ the bleaching of TBA-DASA-POM-DASA is found to be irreversible. We are currently exploring the use of arylamines in the synthetic pathway in order to improve the reversibility of the POM/DASA hybrid. Lastly, attempts were also performed in the solid-state. Unfortunately, in contrast with the POM/Spiro assemblies which can be switched in these conditions, ${ }^{[14]}$ the bleaching of TBA-DASA-POM-DASA under visible light irradiation was not observed.

Influence of the nature of the countercation on the optical properties

One of the major advantages of POM chemistry is that the properties and the physico-chemical features of a hybrid compound can be tuned by modifying the nature of the countercations. In this sense, two new photoactive compounds have been isolated. First, the Na-DASA-POMDASA POM/DASA sodium salt was obtained by reacting TBA-DASA-POM-DASA with an excess of sodium hexafluorophosphate. The almost complete disappearance of the peaks related to the protons of the TBA cations in the Na-DASA-POM-DASA ${ }^{1} \mathrm{H}$ NMR spectrum evidences their substitution (Figures S25-S26). In the IR spectrum, the stretching bands at 897,921 and $939 \mathrm{~cm}^{-1}$ (terminal $\mathrm{Mo}=\mathrm{O}$ groups) and $638 \mathrm{~cm}^{-1}$ (Mo-O-Mo) confirm the integrity of the inorganic platform (Figure S27). As expected, the solubility of the resulting POM/DASA hybrid is strongly modified, TBADASA-POM-DASA being only soluble in organic solvent while Na-DASA-POM-DASA is water-soluble. Noticeably, the initial reddish aqueous solution of Na-DASA-POM-DASA 
is almost discolored after 9 min without irradiation (Figure S28). Thus, Na-DASA-POM-DASA is

a)

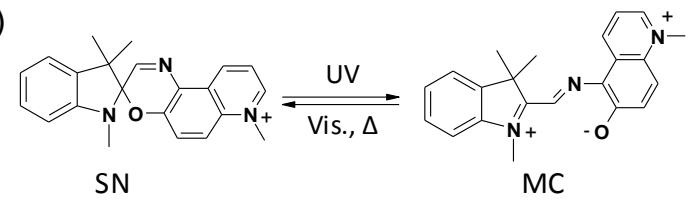

b)

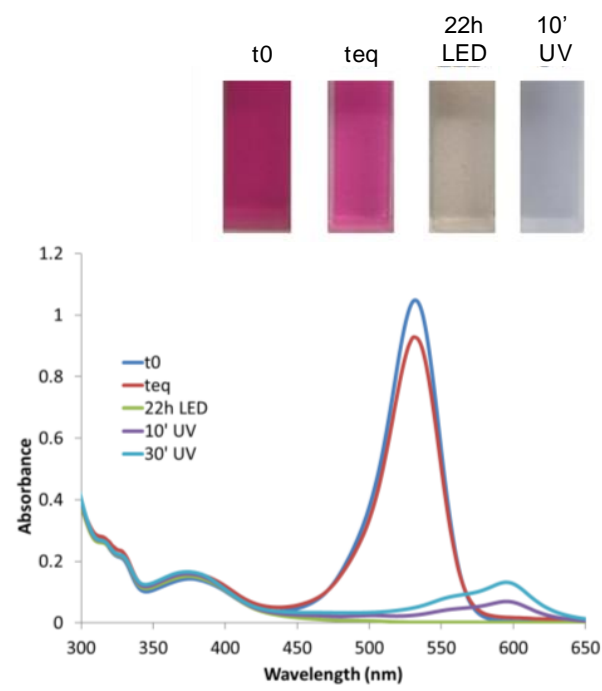

Figure 4. a) Representation of the spironaphtoxazine cations $\mathrm{SN}^{+}$and the corresponding merocyanine form (MC), b) Evolution of the UV-Vis spectra of an acetonitrile solution of SN-DASA-POM-DASA: i) initial solution (t0), ii) after dark equilibrium (teq), iii) after $22 \mathrm{~h}$ of visible light irradiation with LED (525 nm) and iv) after UV light irradiation (10' UV and 30' UV) with the corresponding pictures of the solution during experiments.

essentially stabilized in the cyclopentenone form in aqueous solution, as confirmed by the mere presence of the two characteristic peaks in the 6-9 ppm range in the ${ }^{1} \mathrm{H}$ NMR spectrum (Figure S26). In line with previous reports, this can be explained by great stabilization of the hydrophilic cyclopentenone isomer in water, underlining the crucial role of the solvent on the equilibrium. ${ }^{[10 \mathrm{~b}]}$

Second, responding to one of our goal which is the design of multifunctional optical POM-based materials potentially activated by different stimuli, the metathesis of the TBA cations of TBADASA-POM-DASA with highly photochromic spironaphtoxazine (SN) cations ${ }^{[19]}$ (Figure $4 \mathrm{a}$ ) has been performed as a proof of concept, leading to the SN-DASA-POM-DASA $\left(\mathrm{SN}_{2.9}(\mathrm{TBA})_{0.1}\left[\mathrm{MnMo}_{6} \mathrm{O}_{18}\left\{\left(\mathrm{OCH}_{2}\right)_{3} \mathrm{CNHCO}\left(\mathrm{C}_{16} \mathrm{H}_{22} \mathrm{O}_{5} \mathrm{~N}\right)\right\}_{2}\right]\right)$ compound. Its IR spectrum confirms the presence of both $\mathrm{SN}^{+}$ cations and the inorganic platform (Figure S29). Moreover, the nearly entire replacement of the alkylammonium with $\mathrm{SN}^{+}$ countercations is evidenced by ${ }^{1} \mathrm{H}$ NMR spectroscopy (Figures S30-S33).The spectrum, performed in DMSO due to a lack of solubility of SN-DASA-POM-DASA in acetonitrile at concentrations suitable for such experiments, shows the large predominance of the triene form $(90 \%)$ even once the dark equilibrium is reached. This again highlights that the nature of the solvent strongly modifies the optical behavior of the DASA-POMDASA core. But moreover, UV-Visible studies show that in acetonitrile solutions the bleaching is much faster for SN-DASAPOM-DASA (the loss of intensity of $A_{532}$ being around $76 \%$ after 20 min of visible light irradiation, Figures S34-S35) than for TBADASA-POM-DASA, evidencing the role of the nature of the counterion on the equilibrium. This implies the existence of interactions between the components of the ionic assembly in solution, even at low concentrations. The initial red acetonitrile solution can be fully discolored under visible light irradiation. Then, the resulting solution turned blue under soft UV irradiation $(6 \mathrm{~W}$, $365 \mathrm{~nm}$ ) and switched back to the uncolored state a few seconds after the UV irradiation was stopped. The blue color highlights the formation of the merocyanine isomer (MC) as a result of the UVassisted $\mathrm{C}_{\text {spiro }} \mathrm{O}$ bond cleavage of the spiro form (Figure 4a). At room temperature, this colorless isomer is then thermally recovered. This can be followed by UV-Visible spectroscopy (Figure $4 \mathrm{~b}$ ), the decrease of the band at $532 \mathrm{~nm}$ underlining the disappearance of the colored triene form of the DASA under visible light irradiation while in a second step, the formation of the $\mathrm{MC}$ isomer results in the increase of the band at $600 \mathrm{~nm}$. Importantly, the $365 \mathrm{~nm}$ UV-irradiation only activates the SN entity as the DASA fragment does not absorb in the $350-400 \mathrm{~nm}$ range while green light $(\lambda \approx 530 \mathrm{~nm})$ only affects the DASA counterpart as the initial spiro isomer does not absorb in the visible range. Thus, SN-DASA-POM-DASA represents an orthogonal system based on the covalent assembly of a POM and two organic moieties, a photochrome (SN) and a reverse photochrome (DASA) which can selectively be activated with two distinct optical stimuli (UV or Visible light irradiation) in a similar way than the recently reported organic DASA/azobenzene derivatives. ${ }^{[20]}$ In this sense, SN-DASA-POM-DASA appears more attractive than the yet reported $\{S N-P O M-S P\}$ hybrid ${ }^{[14 c]}$ for which the same stimulus (UV-irradiation) activates simultaneously the two photochromic parts (SN and SP).

\section{Photopolymerization of PEG-DA}

The remarkable molar absorption coefficient value $\left(\varepsilon_{532} \approx 2 \times 10^{5}\right.$ $\left.\mathrm{M}^{-1} \cdot \mathrm{cm}^{-1}\right)$ in the visible domain of TBA-DASA-POM-DASA led us to test this covalent hybrid as a photoinitiator in free-radical polymerization process under visible light, allowing to potentially prepare POM-containing polymers under low-energy irradiation. Indeed, in this field, the few POM-based systems which have been already reported consist in ionic assemblies (POM/onium salts) $)^{[21]}$ and have been used as near-UV photoinitiators $(\lambda<420$ $\mathrm{nm})$. Then, to the best of our knowledge, the implication of hybrid POMs in visible-light induced free-radical polymerization processes remains to be developed. The free-radical photopolymerization of the polyethylene glycol diacrylate (PEGDA) monomer in presence of MDEA (MDEA $=\mathrm{N}$ methyldiethanolamine) considering both TBA-DASA-POMDASA and the Anderson-type POM precursor $(\mathrm{TBA})_{3}\left[\mathrm{MnMo}_{6} \mathrm{O}_{18}\left\{\left(\mathrm{OCH}_{2}\right)_{3} \mathrm{CNH}_{2}\right\}_{2}\right] \quad\left(\mathrm{TBA}-\mathrm{NH}_{2}-\mathbf{P O M}-\mathrm{NH}_{2}\right)^{[22]}$ as photoinitiators was studied by following using RT-FTIR the decrease of the band of the acrylate group at $1637 \mathrm{~cm}^{-1}$. Figure 5 
shows the kinetics of polymerization of five photosensitive formulations, i.e. TBA-NH $\mathbf{N}_{2}-\mathrm{POM}-\mathrm{NH}_{2} / \mathrm{MDEA}$ (Figure 5A), TBA-

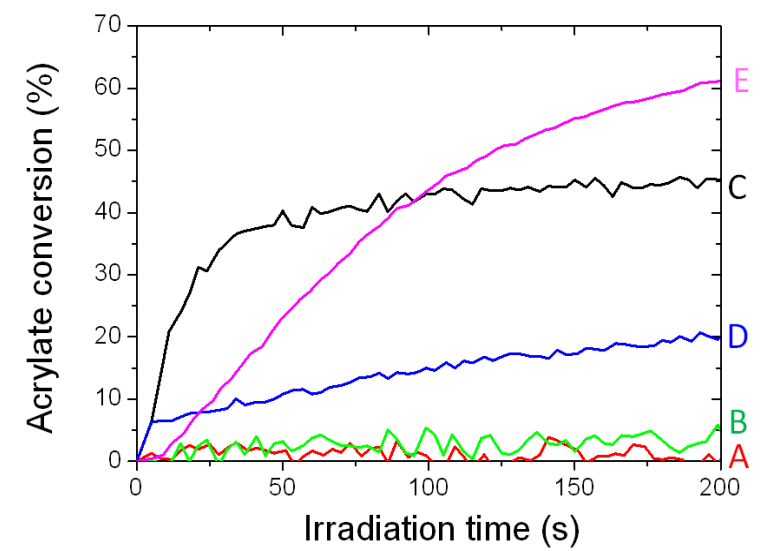

Figure 5. Kinetic profiles of the PEG-DA under visible light exposure $(\lambda>$ $420 \mathrm{~nm}$ ) using A) TBA-NH - -POM-NH $/$ /MDEA, B) TBA-DASA-POMDASA alone, C) TBA-DASA-POM-DASA/MDEA, D) DASA/MDEA and E) $\mathrm{CQ} / \mathrm{MDEA}$ as photoinitiating systems in laminated conditions. Lamp Xenon with a LP $420 \mathrm{~nm}$ filter. Thickness of the coatings $=100 \mu \mathrm{m}$.

DASA-POM-DASA (Figure 5B), TBA-DASA-POM-DASA/MDEA (Figure 5C), DASA ${ }^{[10 \mathrm{~b}]} / \mathrm{MDEA}$ (Figure 5D, DASA corresponding to a pure organic compound as shown in Figure 1 with $\mathrm{R}=\mathrm{R}^{\prime}=\mathrm{Et}$ ) and $\mathrm{CQ}(\mathrm{CQ}=$ camphorquinone)/MDEA (Figure $5 \mathrm{E}$ ) as a reference type II photoinitiating system under visible light irradiation $\left(\lambda_{\text {irr }}>420 \mathrm{~nm}\right.$ ). After $200 \mathrm{~s}$ of irradiation, no photopolymerization occurs neither for TBA-NH $\mathbf{N H}_{2}-\mathbf{P O M}$ $\mathrm{NH}_{2} / \mathrm{MDEA}$ nor TBA-DASA-POM-DASA alone. Under the same conditions, DASA/MDEA leads to a low acrylate conversion (20\%). Interestingly, $45 \%$ of the acrylate functions were consumed with TBA-DASA-POM-DASA/MDEA photoinitiating system, thus clearly highlighting the positive synergic effect between DASA and POM for initiating the free-radical photopolymerization of PEG-DA under visible light irradiation. It is interesting to notice that under the light irradiation conditions, the photoinduced TBA-DASA-POM-DASA/MDEA coatings are coloured and a pink hue persists. Surprisingly, the efficiency of TBA-DASA-POM-DASA/MDEA photoinitiating system as regard to the free radical photopolymerization of PEG-DA appears similar as the well-reported CQ/MDEA system.

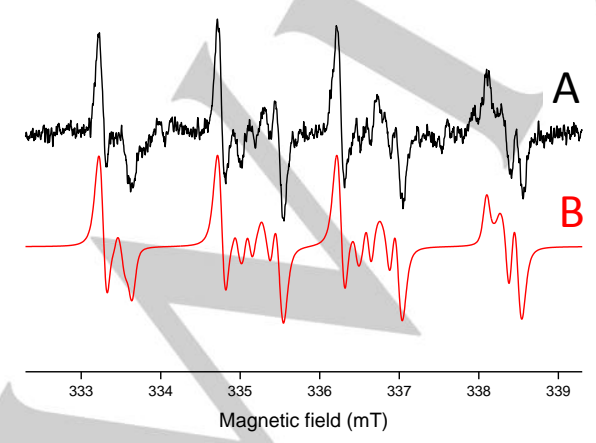

Figure 6. Experimental (A) and simulated (B) EPR spectra monitored after 1800 s LED@VIS irradiation $(\lambda>420 \mathrm{~nm})$ of TBA-DASA-POMDASA/MDEA/acetronitrile/argon solution in the presence of the DMPO spin trapping agent.

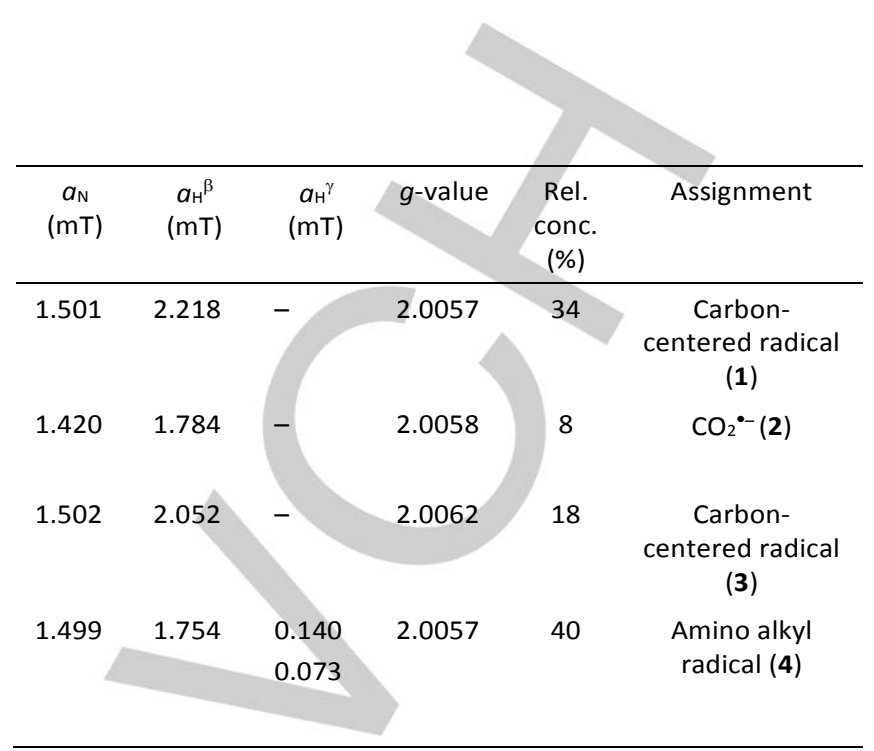

Table 1. Spin-Hamiltonian parameters of DMPO-adducts elucidated from the simulation of experimental spectrum monitored in TBADASA-POM-DASA/MDEA/acetonitrile/argon solution in the presence of DMPO spin trap upon visible light exposure.

After being excited $(\lambda>420 \mathrm{~nm})$ in the presence of MDEA, the photolysis of CQ leads to the formation of both radicals derived from the carbonyl compound (ketyl type radical) and amino alkyl radicals via an $\mathrm{H}$-abstraction mechanism. ${ }^{[23]}$ The final conversion reaches $60 \%$, however the initiation rate with CQ/MDEA is lower than that of TBA-DASA-POM-DASA/MDEA one. The experimental EPR spectrum of a deaerated TBA-DASA-POM-DASA/MDEA acetonitrile solution in presence of DMPO (DMPO $=5,5$ dimethylpyrroline- $N$-oxide) and upon visible light exposure is displayed together with the simulated spectrum in Figure 6. Table 1 summarizes the spin-Hamiltonian parameters of DMPOadducts determined from the simulation of the experimental spectrum. It reveals the presence of four individual signals assigned to the DMPO spin-adducts of carbon-centered radicals (1 and 3), $\mathrm{CO}_{2}{ }^{--}$radical anion (2) and amino alkyl radical (4). ${ }^{[24]}$ By comparison with the EPR spectrum of TBA-DASA-POMDASA recorded in acetonitrile under visible light irradiation but in absence of MDEA (Figure S36), it can be assessed that the carbon-centered radical 1 and $\mathrm{CO}_{2}{ }^{\circ-}$ radical anion 2 result from the photoisomerization of the DASA ligand. The additional signals observed in presence of MDEA, i.e., a carbon-centered radical 3 and an amino alkyl radical 4, confirm that under visible-light activation a dye-sensitized reaction occurs via an $\mathrm{H}$-abstraction mechanism between TBA-DASA-POM-DASA and MDEA. Thus, the generated amino alkyl radical can initiate the free-radical polymerization of PEG-DA, ${ }^{[23]}$ in agreement with the kinetic profile described in Figure 5. Lastly, EPR measurements were performed on pure organic systems. The visible light irradiation of DASA alone does not reveal the formation of any radicals (Figure S37a). When DASA is coupled with MDEA, the generation of aminoalkyl radicals is suspected (Figure S37b) but at a lower concentration compared to the DASA-POM-DASA/MDEA system. 
This difference can fully explain the higher acrylate conversion and the higher reactivity of DASA-POM-DASA/MDEA photoinitiating system towards acrylate monomer than the DASA one. It thus appears that the reported complex constitutes a highly efficient visible-light photoinitiator, and that the strategy described herein must allow the preparation of POM-incorporating polymers under low-energy irradiation.

The macroscopic mechanical properties of PEG-DA derived materials based on CQ/MDEA, DMPA ${ }^{[23]} \quad$ (DMPA $=2,2-$ Dimethoxy-2-phenylacetophenone, a well-known free radical photoinitiator absorbing in the UV range) and TBA- DASA-POMDASA/MDEA photoinitiating systems were compared and characterized according to tensile tests. The aim is to assess the influence of the introduction of POM-derivative on the mechanical behaviour of PEG-DA films when compared with the other photoreticulated PEG-DA materials obtained with CQ/MDEA and DMPA photoinitiating systems. As the visible light irradiation $(\lambda>$ $420 \mathrm{~nm}$ ) does not allow the formation of materials strong enough (thickness $>0.5 \mathrm{~mm}$ ) for the analysis of their mechanical properties, we decided to irradiate the PEG-DA photosensitive systems under a polychromatic $\mathrm{Hg}$-Xe lamp. Figure 7 shows for each sample, a characteristic stress $\sigma_{\mathrm{r}} v s$. strain $\varepsilon_{\mathrm{r}}$ plot. The average $\sigma_{r}$ (stress at break), $\varepsilon_{r}$ (strain at break), and young modulus values obtained from the tensile tests are summarized in Table 2. The resulting CQ-based materials are too brittle and no traction tests could be performed. According to Table 2 and Figure 7, the photo-reticulation of PEG-DA with DMPA induces the formation of materials with higher young modulus than materials containing TBA-DASA-POM-DASA/MDEA. The materials are therefore more rigid and the maximum strain $\varepsilon_{r}$, is around $6 \%$. Interestingly, the addition of TBA-DASA-POMDASA/MDEA in the photoreticulated films leads to a decrease of the young modulus value but yet increases by a factor of 2 the maximum strain $\varepsilon_{r}$ at break, when compared to the neat PEG-DA polymer film containing DMPA.

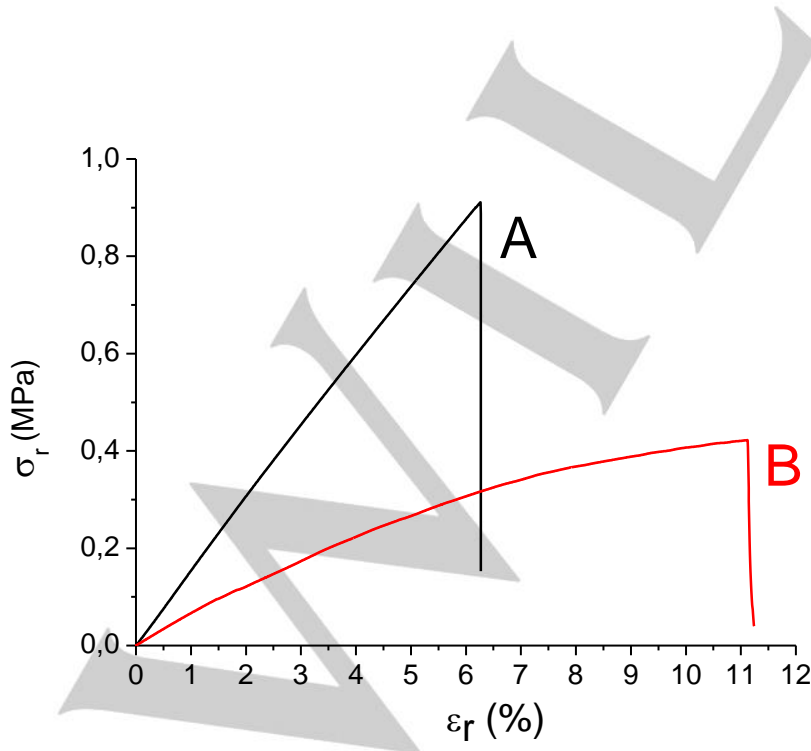

Figure 7 Stress $\sigma_{\mathrm{r}}$ as a function of the strain $\varepsilon_{\mathrm{r}}$ obtained by tensile tests for the photoinduced PEG-DA materials based on A) DMPA and B) TBADASA-POM-DASA/MDEA photoinitiating systems.

\begin{tabular}{cccc}
\hline $\begin{array}{c}\text { Photoinitiating } \\
\text { systems }\end{array}$ & $\begin{array}{c}\text { Young Modulus } \\
\text { (MPa) }\end{array}$ & $\begin{array}{c}\text { Stress at } \\
\text { break (MPa) }\end{array}$ & $\begin{array}{c}\text { Strain at } \\
\text { break (\%) }\end{array}$ \\
\hline DMPA & $16.23 \pm 1.13$ & $0.91 \pm 0.11$ & $6.26 \pm 1.3$ \\
$\begin{array}{c}\text { TBA-DASA-POM- } \\
\text { DASA/MDEA }\end{array}$ & $6.67 \pm 0.18$ & $0.42 \pm 0.10$ & $11.24 \pm 1.3$ \\
\hline
\end{tabular}

Table 2 Young modulus E, stress at break $\sigma_{\mathrm{r}}$ and strain at break $\varepsilon_{\mathrm{r}}$ obtained by tensile tests for the photoinduced PEG-DA materials based on DMPA and TBA-DASA-POM-DASA/MDEA photoinitiating systems

\section{Conclusions}

In conclusion, TBA-DASA-POM-DASA, which represents the first reverse photochrome/POM system, has been obtained. This hybrid is made of two DASA molecules covalently connected to an Anderson-type POM platform. The equilibrium in solution between its colorless cyclopentenone form and the associated highly colored triene conformers has been thoroughly investigated. It has been shown that not only the nature of the solvent but also the nature of the countercations plays a crucial role on the optical properties of this hybrid. Furthermore, this reverse photochromic complex has been associated ionically with photochromic spironaphtoxazine entities, affording the SNDASA-POM-DASA species. It has been shown as a proof of concept that the SN and DASA entities can be selectively activated with two distinct optical stimuli, this being of primary importance for the design of new multifunctional POM-based optical materials. Unfortunately, like almost all non-POM hybrid organic-inorganic DASA systems, the bleaching of the title complex is not reversible. In order to overcome this problem, we are now working to synthesize derivatives of TBA-DASA-POMDASA starting from arylamines, as this should lead to POM incorporating second generation DASA with highly improved reversibility. ${ }^{118,25]}$ We also demonstrated that the exceptional absorbance properties of TBA-DASA-POM-DASA render it suitable as a new efficient photoinitiating system when coupled with MDEA for the free-radical polymerization of acrylate monomers and this under visible light irradiation. The elaboration of polyoxometalate-containing polymers following the photopolymerization approach described herein demonstrated interesting mechanical properties; the addition of TBA-DASAPOM-DASA within the PEG-DA matrix results in an increase of its mechanical resistance by toughening the matrix. This unprecedented investigation opens the gate for the synthesis of newly POM-derivative materials.

\section{Experimental Section}

General remarks 
All available chemicals were purchased from commercial chemical suppliers and used as received. The Mn-Anderson type polyoxomolybdate (TBA $)_{3}\left[\mathrm{MnMo}_{6} \mathrm{O}_{18}\left\{\left(\mathrm{OCH}_{2}\right)_{3} \mathrm{CNHCO}\left(\mathrm{CH}_{2} \mathrm{Cl}\right)\right\}_{2}\right]_{1}{ }_{16}$ a] the activated furan $\left(\mathrm{C}_{11} \mathrm{H}_{10} \mathrm{O}_{5}\right),{ }^{[10 a]}$ the pure organic DASA ${ }^{[10 \mathrm{~b}]}$ which is obtained by reaction of the activated furan and diethylamine, the spironaphtoxazine SNI[19], and (TBA $)_{3}\left[\mathrm{MnMo}_{6} \mathrm{O}_{18}\left\{\left(\mathrm{OCH}_{2}\right)_{3} \mathrm{CNH}_{2}\right\}_{2}\right]^{[22]}\left(\right.$ TBA-N $\left.\mathrm{NH}_{2}-\mathrm{POM}-\mathrm{NH}_{2}\right)$ used herein were synthesized as previously described. Polyethylene glycol (PEG$\mathrm{DA}, \mathrm{Mw}=400 \mathrm{~g} \cdot \mathrm{mol}^{-1}$, SR344) was used as an acrylate reactive monomer and was kindly provided by Sartomer. N-Methyl diethanolamine (MDEA, used as received without further purification), 5,5-dimethyl-1-pyrroline $\mathrm{N}$-oxide (DMPO, distilled before application) and camphorquinone (CQ) were purchased from Sigma-Aldrich. 2,2-Dimethoxy-2-phenylacetophenone (DMPA) was provided for BASF. Elemental analyses were performed by the Service Central d'Analyse of CNRS, 91198 Gif sur Yvette, France. Infrared spectra (ATR) were recorded on an IRFT Nicolet 6700 apparatus. Relative intensities are given after the wavenumber as vs $=$ very strong, $\mathrm{s}=$ strong, $\mathrm{m}=$ medium, $\mathrm{w}=$ weak, $\mathrm{sh} .=$ shoulder, $\mathrm{br}=$ broad. NMR spectra of (TBA $)_{3}\left[\mathrm{MnMo}_{6} \mathrm{O}_{18}\left\{\left(\mathrm{OCH}_{2}\right)_{3} \mathrm{CNHCOCH}_{2} \mathrm{NHC}_{4} \mathrm{H}_{9}\right\}_{2}\right], \quad$ Na-DASA-POMDASA and SN-DASA-POM-DASA were recorded on a Bruker Avance 300 spectrometer operating at $300 \mathrm{MHz}$ for ${ }^{1} \mathrm{H}$ and $75 \mathrm{MHz}$ for ${ }^{13} \mathrm{C}$ nuclei. NMR spectra of TBA-DASA-POM-DASA were recorded on a Bruker Avance 400 spectrometer operating at $400 \mathrm{MHz}$ for ${ }^{1} \mathrm{H}$ and $100 \mathrm{MHz}$ for ${ }^{13} \mathrm{C}$ nuclei. Chemical shifts are expressed in parts per million (ppm) downfield from internal TMS. The following abbreviations were used to explain the multiplicities: s, singlet; $d$, doublet; $t$, triplet; br, broad peaks; m, multiplet or overlapping peaks.

NB: In order to clarify the attributions of the signals in the 6-8 ppm range of the ${ }^{1} \mathrm{H}$ NMR spectra (for TBA-DASA-POM-DASA and SN-DASA-POMDASA), DASA $A$ stands for the colored triene isomer (both conformers) whereas $D A S A_{B}$ stands for the colorless cyclopentenone isomer.

\section{Synthetic procedures}

\section{Synthesis of (TBA) $3\left[\mathrm{MnMo}_{6} \mathrm{O}_{18}\left\{\left(\mathrm{OCH}_{2}\right)_{3} \mathrm{CNHCOCH}_{2} \mathrm{NHC}_{4} \mathrm{H}_{9}\right\}_{2}\right]$}

To a clear solution of $(\mathrm{TBA})_{3}\left[\mathrm{MnMo}_{6} \mathrm{O}_{18}\left\{\left(\mathrm{OCH}_{2}\right)_{3} \mathrm{CNHCO}\left(\mathrm{CH}_{2} \mathrm{Cl}\right)\right\}_{2}\right](300$ $\mathrm{mg}, 0.15 \mathrm{mmol}$ ) and tetrabutylammonium iodide TBAI $(108 \mathrm{mg}, 0.30 \mathrm{mmol})$ in $5 \mathrm{~mL}$ of acetonitrile, were added 1-butylamine $(58 \mu \mathrm{L}, 0.59 \mathrm{mmol})$ and solid sodium carbonate $\mathrm{Na}_{2} \mathrm{CO}_{3}(39 \mathrm{mg}, 0.37 \mathrm{mmol}$ ). The mixture was stirred in refluxing acetonitrile for $36 \mathrm{~h}$. The suspension was then cooled to room temperature and centrifuged. The clear solution was added to a large volume of diethylether, inducing the precipitation of the product. The solid was filtrated, redissolved in a minimum amount of acetonitrile and precipitated again in diethyl ether. The solid was finally filtrated, washed with $2 \times 2 \mathrm{~mL}$ of water, $2 \times 2 \mathrm{~mL}$ of ethanol and $2 \times 3 \mathrm{~mL}$ of diethylether, and finally dried under vacuum. (TBA) $)_{3}\left[\mathrm{MnMo}_{6} \mathrm{O}_{18}\left\{\left(\mathrm{OCH}_{2}\right)_{3} \mathrm{CNHCOCH}_{2} \mathrm{NHC}_{4} \mathrm{H}_{9}\right\}_{2}\right]$ was obtained as an orange powder. Yield: $207 \mathrm{mg}, 0.10 \mathrm{mmol}, 67 \%$.

${ }^{1} \mathrm{H}$ NMR $\delta\left(\mathrm{ppm}, \mathrm{CD}_{3} \mathrm{CN}\right): 65.45\left(\mathrm{br}, 12 \mathrm{H},\left(\mathrm{OCH}_{2}\right)_{3} \mathrm{C}-\mathrm{N}\right), 8.25(\mathrm{br}, 2 \mathrm{H},(\mathrm{O}) \mathrm{C}-$ $\mathrm{NH}$-C, amide), 3.41 (s, $\left.4 \mathrm{H},-\mathrm{CH}_{2}-\mathrm{C}(\mathrm{O})\right), 3.13(\mathrm{~m}, 24 \mathrm{H}, \mathrm{H}$ твA), 2.55 (br, $4 \mathrm{H}$, $\left.\mathrm{N}-\mathrm{CH}_{2}-\mathrm{CH}_{2}\right), 1.62(\mathrm{~m}, 24 \mathrm{H}, \mathrm{H}$ TBA $), 1.40\left(\mathrm{~m}, 32 \mathrm{H}, \mathrm{H}_{\text {TBA }}+\mathrm{N}-\mathrm{CH}_{2}-\mathrm{CH}_{2}-\mathrm{CH}_{2}+\right.$ $\left.\mathrm{N}-\mathrm{CH}_{2}-\mathrm{CH}_{2}-\mathrm{CH}_{2}\right), 1.00\left(\mathrm{~m}, 42 \mathrm{H}, \mathrm{H}\right.$ TBA $\left.+\mathrm{N}-\mathrm{CH}_{2}-\mathrm{CH}_{2}-\mathrm{CH}_{2}-\mathrm{CH}_{3}\right)$

${ }^{13} \mathrm{C}$ NMR $\delta\left(\mathrm{ppm}, \mathrm{CD}_{3} \mathrm{CN}\right): 173.7(-\mathrm{HN}-\mathrm{C}(\mathrm{O})), 59.4\left(\mathrm{C}_{\mathrm{TBA}}\right), 51.7\left((\mathrm{O}) \mathrm{C}-\mathrm{CH}_{2}-\right.$ $\mathrm{NH}), 50.3\left(\mathrm{HN}-\mathrm{CH}_{2}\right), 33.2\left(-\mathrm{CH}_{2}-\mathrm{CH}_{2}-\mathrm{CH}_{3}\right), 24.4\left(\mathrm{C}_{\mathrm{TBA}}\right), 21.5\left(-\mathrm{CH}_{2}-\mathrm{CH}_{3}\right)$, 20.6 (Ства), $14.7\left(-\mathrm{CH}_{3}\right), 14.1$ (С

IR (ATR) : v $\left(\mathrm{cm}^{-1}\right) 3477$ ( $\mathrm{w}, \mathrm{v} \mathrm{N}-\mathrm{H}$ amine), 3310 ( $\mathrm{w}, \mathrm{v} \mathrm{N}-\mathrm{H}$ amide), 2959 (m, v C-H), $2933(\mathrm{~m}, \vee \mathrm{C}-\mathrm{H}), 2872(\mathrm{~m}, \vee \mathrm{C}-\mathrm{H}), 1682(\mathrm{~s}, \mathrm{v} \mathrm{CO}), 1510(\mathrm{~m})$, $1480(\mathrm{~m}), 1380(\mathrm{w}), 1061(\mathrm{~m}), 1026(\mathrm{~m}), 931$ (vs, v Mo=O), 917 (vs, v $\mathrm{Mo}=\mathrm{O}$ ), 900 (vs, v Mo=O), 647 (vs, v Mo-O-Mo)

Anal. Calcd for $\mathrm{MnMo}_{6} \mathrm{O}_{26} \mathrm{C}_{68} \mathrm{H}_{146} \mathrm{~N}_{7}$ (2108.6): C, 38.69; $\mathrm{H}, 6.92 ; \mathrm{N}, 4.65$. Found : C, 38.24; H, 6.82; N, 4.55 .

Synthesis of $(\mathrm{TBA})_{3}\left[\mathrm{MnMO}_{6} \mathrm{O}_{18}\left\{\left(\mathrm{OCH}_{2}\right)_{3} \mathrm{CNHCO}\left(\mathrm{C}_{16} \mathrm{H}_{22} \mathrm{O}_{5} \mathrm{~N}\right)\right\}_{2}\right]$ (TBADASA-POM-DASA)
To a yellow DMF solution $(4 \mathrm{~mL})$ of the activated furan $\left(\mathrm{C}_{11} \mathrm{H}_{10} \mathrm{O}_{5}, 526 \mathrm{mg}\right.$, $2.37 \mathrm{mmol}$ ), was slowly added an orange DMF solution $(4 \mathrm{~mL})$ of the secondary amine functionalized Anderson-type $\mathrm{POM}$ (TBA $)_{3}\left[\mathrm{MnMo}_{6} \mathrm{O}_{18}\left\{\left(\mathrm{OCH}_{2}\right)_{3} \mathrm{CNHCOCH}_{2} \mathrm{NHC}_{4} \mathrm{H}_{9}\right\}_{2}\right]$ (500 mg, $\left.0.24 \mathrm{mmol}\right)$. The solution turned red immediately and was stirred overnight at room temperature. Then, it is poured onto a large volume of diethylether inducing the precipitation of a solid which was isolated by centrifugation. Two other dissolution (in a minimum amount of acetonitrile)/precipitation (in diethylether) cycles allowed the purification of the targeted product (excess of the activated furan was discarded in this last treatment). TBADASA-POM-DASA was isolated as a dark red solid. Yield: $541 \mathrm{mg}, 0.21$ $\mathrm{mmol}, 88 \%$

${ }^{1} \mathrm{H}$ NMR $\delta\left(\mathrm{ppm}, \mathrm{CD}_{3} \mathrm{CN}\right): 65.36$ (br, $\left.12 \mathrm{H},\left(\mathrm{OCH}_{2}\right)_{3} \mathrm{C}-\mathrm{N}\right), 11.38(\mathrm{~s},-\mathrm{OH})$ $7.80\left(\mathrm{~d}, \mathrm{DASA}_{\mathrm{B}}\right), 7.70\left(\mathrm{~d}, \mathrm{DASA}_{\mathrm{A}}\right), 7.58\left(\mathrm{~d}, \mathrm{DASA}_{\mathrm{A}}\right), 7.00\left(\mathrm{~m}, \mathrm{DASA}_{\mathrm{A}}\right), 6.84$ (s, DASA $\left.A_{A}\right), 6.30$ (d, DASA $\left.A_{B}\right), 6.16\left(\mathrm{~m}, \mathrm{DASA}_{\mathrm{A}}\right), 4.69\left(\mathrm{~s},-\mathrm{NCH}_{2}(\mathrm{C}=\mathrm{O})\right), 3.51$ (s, $\left.\mathrm{NCH}_{2} \mathrm{CH}_{2}-\right), 3.12$ (m, TBA), $1.66\left(\mathrm{~m},\left(\mathrm{TBA}+\mathrm{DASA}\left(\mathrm{CH}_{3} \mathrm{C}-\right)+\right.\right.$ $\mathrm{NCH}_{2} \mathrm{CH}_{2} \mathrm{CH}_{2}$ ), 1.39 (m, TBA + $\left.\left.-\mathrm{CH}_{2} \mathrm{CH}_{2} \mathrm{CH}_{3}\right)\right), 0.99$ (m, TBA + $\left.\mathrm{CH}_{2} \mathrm{CH}_{3}\right)$ ).

${ }^{13} \mathrm{C}$ NMR $\delta\left(\mathrm{ppm}, \mathrm{CD}_{3} \mathrm{CN}\right): 204.9$ (DASA $\left.A_{B}\right), 168.0$ (DASA $), 166.6$ $\left(\mathrm{DASA}_{B}\right), 165.5\left(\mathrm{DASA}_{\mathrm{A}}\right), 164.2\left(\mathrm{DASA}_{\mathrm{B}}\right), 164.1\left(\mathrm{DASA}_{\mathrm{A}}\right), 162.9\left(\mathrm{DASA}_{\mathrm{A}}\right)$ $160.0\left(\mathrm{DASA}_{\mathrm{B}}\right), 154.5\left(\mathrm{DASA}_{\mathrm{A}}\right), 154.0\left(\mathrm{DASA}_{\mathrm{A}}\right), 145.6\left(\mathrm{DASA}_{\mathrm{A}}\right), 145.4$ $\left(\mathrm{DASA}_{\mathrm{A}}\right), 136.9\left(\mathrm{DASA}_{\mathrm{A}}\right), 136.3\left(\mathrm{DASA}_{\mathrm{A}}\right), 135.4\left(\mathrm{DASA}_{B}\right), 106.9\left(\mathrm{DASA}_{B}\right)$ $104.8\left(\mathrm{DASA}_{\mathrm{A}}\right), 104.5\left(\mathrm{DASA}_{\mathrm{A}}\right), 103.7\left(\mathrm{DASA}_{\mathrm{A}}\right), 89.6\left(\mathrm{DASA}_{\mathrm{A}}\right), 89.1$ (DASA $\left.A_{A}\right), 68.1$ (DASAB), 59.7, 59.2 (СтвA), 57.0, 54.7, 53.6, 52.1, 50.4,

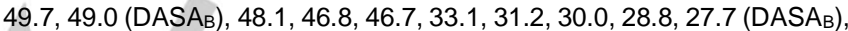
26.7 (DASA $\left.A_{A}\right), 24.3$ (С IR (ATR) : v $\left(\mathrm{cm}^{-1}\right) 3324$ (w, v N-H amide), 2960 (m, v C-H), 2935 (m, v CH), 2873 ( $m, v \mathrm{C}-\mathrm{H}), 1693$ ( $\mathrm{m}, \mathrm{v} \mathrm{CO}), 1606$ (s, v C=C olefinic part), 1487 (s), 1347 (vs, $\delta$ C-O), 1193 (m), 1138 (vs, v C-O), 940 (vs, v Mo=O), 917 ( $v s$, v Mo=O), 900 (vs, v Mo=O), 657 (vs, v Mo-O-Mo).

Anal. Calcd for $\mathrm{MnMo}_{6} \mathrm{O}_{36} \mathrm{C}_{90} \mathrm{H}_{166} \mathrm{~N}_{7}$ (2553.0): C, 42.34; $\mathrm{H}, 6.55 ; \mathrm{N}, 3.84$ Found : C, $41.20 ; \mathrm{H}, 6.45 ; \mathrm{N}, 3.83$.

\section{Synthesis of $\mathrm{Na}_{3}\left[\mathrm{MnMo}_{6} \mathrm{O}_{18}\left\{\left(\mathrm{OCH}_{2}\right)_{3} \mathrm{CNHCO}\left(\mathrm{C}_{16} \mathrm{H}_{22} \mathrm{O}_{5} \mathrm{~N}\right)\right\}_{2}\right]$ (Na-DASA- POM-DASA)}

An acetonitrile solution $(0.7 \mathrm{~mL}$, the solution is gently heated to obtain a clear solution) of TBA-DASA-POM-DASA $(50 \mathrm{mg}, 0.020 \mathrm{mmol}$ ) was slowly added to an acetonitrile solution $(1.5 \mathrm{~mL})$ of sodium hexafluorophosphate $\mathrm{NaPF}_{6}(66 \mathrm{mg}, 0.392 \mathrm{mmol})$. The resulting suspension was stirred at room temperature during $1.5 \mathrm{~h}$ before it was filtered, washed with a few drops of acetonitrile and diethylether. NaDASA-POM-DASA was obtained as a dark red powder. Yield: $33 \mathrm{mg}$ $0.017 \mathrm{mmol}, 87 \%$

${ }^{1} \mathrm{H}$ NMR $\delta\left(\mathrm{ppm}, \mathrm{D}_{2} \mathrm{O}\right): 64.60$ (br, 12H, $\left.\left(\mathrm{OCH}_{2}\right)_{3} \mathrm{C}-\mathrm{N}\right), 7.61(\mathrm{~d}, 2 \mathrm{H}), 6.58(\mathrm{~d}$, 2H), 4.84 (br, 2H), 4.36 (br, 4H, N-CH $-\mathrm{C}(\mathrm{O})-$ ), 3.52 (br, 2H), 3.21 (br, $4 \mathrm{H}$, $\left.\mathrm{N}-\mathrm{CH}_{2}-\mathrm{CH}_{2}-\right), 1.58\left(\mathrm{br}, 16 \mathrm{H}, \mathrm{N}-\mathrm{CH}_{2}-\mathrm{CH}_{2}-\mathrm{CH}_{2}-\mathrm{CH}_{3}+-\mathrm{C}\left(\mathrm{CH}_{3}\right)_{2}\right), 1.24(\mathrm{br}$ $\left.4 \mathrm{H}, \mathrm{N}-\mathrm{CH}_{2}-\mathrm{CH}_{2}-\mathrm{CH}_{2}-\mathrm{CH}_{3}\right), 0.78\left(\mathrm{br}, 6 \mathrm{H}, \mathrm{N}-\mathrm{CH}_{2}-\mathrm{CH}_{2}-\mathrm{CH}_{2}-\mathrm{CH}_{3}\right.$ ).

(NB: in solution, Na-DASA-POM-DASA essentially exists in the cyclopentenone form.)

IR (ATR): v (cm $\left.{ }^{-1}\right) 3379$ (w, v N-H amide), 1692 (m, v CO), 1597 (m), 1500 $(\mathrm{m}), 1359$ (s), 1146 (s), 1021 (w), 939 (vs, v Mo=O), 921 (vs, v Mo=O), 896 (vs, v Mo=O), 637 (vs, v Mo-O-Mo)

\section{Synthesis of $\mathrm{SN}_{2.9}(\mathrm{TBA})_{0.1}\left[\mathrm{MnMo}_{6} \mathrm{O}_{18}\left\{\left(\mathrm{OCH}_{2}\right)_{3} \mathrm{CNHCO}\left(\mathrm{C}_{16} \mathrm{H}_{22} \mathrm{O}_{5} \mathrm{~N}\right)\right\}_{2}\right]$ (SN-DASA-POM-DASA)}

A clear solution of SNI (150 mg, $0.318 \mathrm{mmol}$ ) in a chloroform/acetonitrile $(1 / 2)$ cosolvent $(10 \mathrm{~mL})$ was obtained after gently heating. Then, a solution of TBA-DASA-POM-DASA ( $41 \mathrm{mg}, 0.016 \mathrm{mmol}$ ) in $2 \mathrm{ml}$ of acetonitrile was slowly added, inducing an instantaneous precipitation. The suspension was stirred at room temperature for $1 \mathrm{~h}$ before filtration. The solid was then washed with a few drops of acetonitrile and diethylether. SN-DASA-POMDASA was obtained as a dark red powder. Yield: $44 \mathrm{mg}, 0.015 \mathrm{mmol}$, $96 \%$.

${ }^{1} \mathrm{H}$ NMR $\delta$ (ppm, DMSO-d6): 65.14 (s, br., $\left.\left(\mathrm{OCH}_{2}\right)_{3} \mathrm{C}-\mathrm{N}\right), 11.30$ (s, -OH), $9.60(\mathrm{~d}, \mathrm{SN}), 9.36(\mathrm{~d}, \mathrm{SN}), 8.63\left(\mathrm{~s}, \mathrm{br} ., \mathrm{DASA}_{\mathrm{B}}\right), 8.39(\mathrm{~d}, \mathrm{SN}), 8.17(\mathrm{~s}, \mathrm{SN})$, 
$8.10\left(\mathrm{~d}, \mathrm{DASA}_{\mathrm{A}}\right), 7.93(\mathrm{~d}, \mathrm{SN}), 7.88\left(\mathrm{~d}, \mathrm{DASA}_{\mathrm{A}}\right), 7.54$ (s, br., DASA $), 7.20$ $\left(\mathrm{m}, \mathrm{SN}+\mathrm{DASA}_{\mathrm{A}}\right), 7.12\left(\mathrm{~d}, \mathrm{DASA}_{\mathrm{A}}\right), 6.88(\mathrm{t}, \mathrm{SN}), 6.73(\mathrm{~d}, \mathrm{SN}), 6.67(\mathrm{~d}$, $\left.\mathrm{DASA}_{\mathrm{A}}\right), 6.10\left(\mathrm{t}, \mathrm{DASA}_{\mathrm{A}}\right), 4.60\left(\mathrm{~s}, \mathrm{SN}+-\mathrm{NCH}_{2}(\mathrm{C}=\mathrm{O})\right.$ ) $), 3.49$ (s, br., $\left.\mathrm{NCH}_{2} \mathrm{CH}_{2}-\right), 3.17$ (m, TBA), 2.74 (s, SN), 1.59 (m, TBA + DASA $\left(\mathrm{CH}_{3} \mathrm{C}-\right)+$ $\left.-\mathrm{NCH}_{2} \mathrm{CH}_{2} \mathrm{CH}_{2}-\right), 1.28\left(\mathrm{~m}, \mathrm{TBA}+\mathrm{SN}\left(\mathrm{CH}_{3} \mathrm{C}-\right)+-\mathrm{CH}_{2} \mathrm{CH}_{2} \mathrm{CH}_{3}\right), 0.90(\mathrm{~m}$, $\left.\mathrm{TBA}+-\mathrm{CH}_{2} \mathrm{CH}_{3}\right)$.

${ }^{13} \mathrm{C}$ NMR $\delta$ (ppm, DMSO-d6): 155.6 (CSN), 148.1 (C $\left.\mathrm{C}_{\text {SN }}\right), 146.9$ (CSN), 146.0 (CSN), 143.4 (CDASA), 143.3 (CDASA), 140.0 (CSN), 135.0 (CSN), 134.0 (CSN), 132.8 (C DASA $), 128.0$ (CSN), 127.6 (C (CSN), 122.8 (CSN), 121.6, 121.3 (CsN), 120.1 (CSN), 107.4 (CSN), 102.3

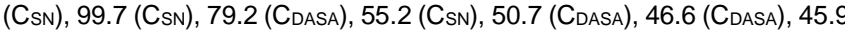
( $\left.\mathrm{C}_{S N}\right), 29.3\left(\mathrm{C}_{S N}\right), 27.5$ (CDASA $), 26.0,25.1\left(\mathrm{C}_{S N}\right), 23.0$ (C 19.4 (C DASA $), 19.2$ (C DASA $), 19.1$ (C DASA $), 19.0$ (C DASA $), 13.8$ (C DASA $), 13.7$ (C.

IR (ATR) : v ( $\left.\mathrm{cm}^{-1}\right) 3300$ (w, v N-H amide), 1690 (m, v CO), 1604 (m), 1485 (s), $1346(\mathrm{~s}), 1278(\mathrm{~m}), 1192(\mathrm{~m}), 1137$ (s), $1049(\mathrm{~m}), 939$ (vs, v Mo=O), 913 (vs, v Mo=O), 897 (vs, v Mo=O), 810 (m), 650 (vs, v Mo-O-Mo). Anal. Calc. for $\mathrm{C}_{107.4} \mathrm{H}_{125.4} \mathrm{MnMo}_{6} \mathrm{~N}_{12.8} \mathrm{O}_{38.9}$ : C, 45.28; $\mathrm{H}, 4.44 ; \mathrm{N}, 6.29$. Found: C, 43.41; H, 4.47; N, 6.06.

\section{Photosensitive formulations}

Four photosensitive formulations have been prepared: the first formulation contains TBA- $\mathrm{NH}_{2}-\mathrm{POM}-\mathrm{NH}_{2}$ / MDEA, the second one refers to TBA-DASA-POM-DASA / MDEA, the third one is DASA / MDEA and the last one corresponds to the reference CQ/MDEA (Photoinitiator / MDEA : $0.5 \mathrm{wt} \% / 5 \mathrm{wt} \%$ in a PEG-DA matrix).

\section{Tensile tests}

The macroscopic mechanical properties of the PEG-DA derivative materials based on three different photoinitiating systems i.e. DMPA (0.5 wt\%), CQ/MDEA (0.5 wt \%/ $5 \mathrm{wt} \%)$ and TBA-DASA-POMDASA/MDEA (0.5 wt $\% / 5$ wt $\%)$ have been tested. Each photosensitive formulation have been introduced in a silicon mold $(3.8 \mathrm{~cm} \times 1.8 \mathrm{~cm} \times 0.1 \mathrm{~cm})$ and irradiated during $200 \mathrm{~s}$ upon a polychromatic $\mathrm{Hg}$-Xe lamp (250W, UV-technik meyer gmbh). The mechanical behavior of the obtained materials was assessed by tensile tests with an Instron 5962 universal testing machine equipped with a force cell of $100 \mathrm{~N}$. For each type of materials, 3 specimens were tested at a speed of $1 \mathrm{~mm} / \mathrm{min}$ at room temperature $\left(23^{\circ} \mathrm{C} \pm 2\right.$ $\left.{ }^{\circ} \mathrm{C}\right)$.

\section{Acknowledgements}

This work was supported by the Ministère de l'Enseignement Supérieur et de la Recherche, the CNRS, the Universite de Versailles Saint Quentin en Yvelines, a public grant overseen by the French National Research Agency (ANR) as part of the "Investissements d'Avenir" program n ${ }^{\circ}$ ANR-11-IDEX-0003-02 and CHARMMMAT ANR-11-LABX-0039 and the DIM RESPORE. This work was also supported by the Slovak Research and Development Agency under the contract No. APVV-15-0053. Vlasta Brezová thanks Ministry of Education, Science, Research and Sport of the Slovak Republic for funding within the scheme "Excellent research teams".

Keywords: Polyoxometalate - Donor-Acceptor Stenhouse Adduct $\cdot$ Photochromism • Photopolymerization

[1] R. Klajn, Chem. Soc. Rev. 2014, 43, 148-184.
[2] H. Tian, S. Yang, Chem. Soc. Rev. 2004, 33, 85-97.

[3] G. Tomasello, M. J. Bearpark, M. A. Robb, G. Orlandi, M. Garavelli, Angew. Chem. Int. Ed. 2010, 49, 2913-2916.

[4] a) M. V. Peters, R. S. Stoll, A. Kühn, S. Hecht, Angew. Chem. Int. Ed. 2008, 47, 5968-5972; b) M. Dong, A. Babalhavaeji, S. Samanta, A. A. Beharry, G. A. Woolley, Acc. Chem. Res. 2015, 48, 2662-2670.

[5] M. Qin, Y. Huang, F. Li, Y. Song, J. Mater. Chem. C 2015, 3, 9265-9275.

[6] M. H. Sharifian, A. R. Mahdavian, H. Salehi-Mobarakeh, Langmuir 2017 33, 8023-8031.

[7] X. Chai, Y.-X. Fu, T. D. James, J. Zhang, X.-P. He, H. Tian, Chem. Commun. 2017, 53, 9494-9497.

[8] C.-Y. Huang, A. Bonasera, L. Hristov, Y. Garmshausen, B. M. Scmidt, D. Jacquemin, S. Hecht, J. Am. Chem. Soc. 2017, 139, 15205-15211.

[9] W. A. Velema, W. Szymanski, B. L. Feringa, J. Am. Chem. Soc. 2014, 136, 2178-2191.

[10] a) S. Helmy, F. A. Leibfarth, S. Oh, J. E. Poelma, C. J. Hawker, J. Read de Alaniz, J. Am. Chem. Soc. 2014, 136, 8169-8172; b) S. Helmy, S. Oh, F. A. Leibfarth, C. J. Hawker, J. Read de Alaniz, J. Org. Chem. 2014, 79, 11316-11329; c) M. M. Lerch, W. Szymanski, B. L. Feringa, Chem. Soc. Rev. 2018, 47, 1910-1937; d) J. Ahrens, T. Bian, T. Vexler, R. Klajn, ChemPhotoChem 2017, 1, 230-236; e) M. Di Donato, M. M. Lerch, A Lapini, A. D. Laurent, A. lagatti, L. Bussotti, S. P. Ihrig, M. Medved', D. Jacquemin, W. Szymański, W. J. Buma, P. Foggi, B. L. Feringa, J. Am Chem. Soc. 2017, 139, 15596-15599; f) M. M. Lerch, M. Di Donato, A D. Laurent, M. Medved', A. lagatti, L. Bussotti, A. Lapini, W. J. Buma, P Foggi, W. Szymański, B. L. Feringa, Angew. Chem. Int. Ed. 2018, 57, 8063-8068; g) O. Rifaie-Graham, S. Ulrich, N. F. B. Galensowske, S Balog, M. Chami, D. Rentsch, J. R. Hemmer, J. Read de Alaniz, L. F. Boesel, N. Bruns, J. Am. Chem. Soc. 2018, 140, 8027-8036; h) J. R. Hemmer, Z. A. Page, K. D. Clark, F. Stricker, N. D. Dolinski, C. J. Hawker, J. Read de Alaniz, J. Am. Chem. Soc. 2018, 140, 10425-10429; i) N. Mallo, E. D. Foley, H. Iranmanesh, A. D. W. Kennedy, E. T. Luis, J. Ho, J. B. Harper, J. E. Beves, Chem. Sci., 2018, 9, 8242-8242.

[11] a) H. N. Miras, L. Vila-Nadal, L. Cronin, Chem. Soc. Rev. 2014, 43, 56795699; b) A. Proust, B. Matt, R. Villanneau, G. Guillemot, P. Gouzerh, G. Izzet, Chem. Soc. Rev. 2012, 41, 7605-7622; c) Y. Ji, L. Huang, J. Hu, C. Streb, Y.-F. Song, Energy Environ. Sci. 2015, 8, 776-789.

[12] J. Xu, H. Volfova, R. J. Mulder, L. Goerigk, G. Bryant, E. Riedle, C Ritchie, J. Am. Chem. Soc. 2018, 140, 10482-10487.

[13] a) P. Mialane, G. Zhang, I. M. Mbomekalle, P. Yu, J.-D. Compain, A Dolbecq, J. Marrot, F. Sécheresse, B. Keita, L. Nadjo, Chem. Eur. J. 2010, 16, 5572-5576; b) J.-D. Compain, P. Deniard, R. Dessapt, A. Dolbecq, O. Oms, F. Sécheresse, J. Marrot, P. Mialane, Chem. Commun 2010, 46, 7733-7735; c) K. Hakouk, O. Oms, A. Dolbecq, J. Marrot, A. Saad, P. Mialane, H. El Bekkachi, S. Jobic, P. Deniard, R. Dessapt, J. Mater. Chem. C 2014, 2, 1628-1641; d) C. Menet, H. Serier-Brault, O Oms, A. Dolbecq, J. Marrot, A. Saad, P. Mialane, S. Jobic, P. Deniard, R. Dessapt, RSC Adv. 2015, 5, 79635-79643.

[14] a) O. Oms, K. Hakouk, R. Dessapt, P. Deniard, S. Jobic, A. Dolbecq, T. Palacin, L. Nadjo, B. Keita, J. Marrot, P. Mialane, Chem. Commun. 2012 48, 12103-12105; b) A. Parrot, G. Izzet, L.-M. Chamoreau, A. Proust, O Oms, A. Dolbecq, K. Hakouk, H. El Bekkachi, P. Deniard, R. Dessapt, P. Mialane, Inorg. Chem. 2013, 52, 11156-11163; c) A. Saad, O. Oms, J. Marrot, A. Dolbecq, K. Hakouk, H. El Bekkachi, S. Jobic,, P. Deniard, R. Dessapt, D. Garrot, K. Boukheddaden, R. Liu, G. Zhang, B. Keita, P. Mialane, J. Mater. Chem. C 2014, 2, 4748-4758; d) A. Saad, O. Oms, A Dolbecq, C. Menet, R. Dessapt, H. Serier-Brault, E. Allard, K. Baczko, P. Mialane, Chem. Commun. 2015, 51, 16088-16091.

[15] J. Harada, Y. Kawazoe, K. Ogawa, Chem. Commun. 2010, 46, 25932595

[16] a) S. Vanhaecht, T. Quanten, T. N. Parac-Vogt, Inorg. Chem. 2017, 56, 3095-3101; b) J. Zhang, J. Luo, P. Wang, B. Ding, Y. Huang, Z. Zhao, J Zhang, Y. Wei, Inorg. Chem. 2015, 54, 2551-2559; c) A. Blazevic, E. AlSayed, A. Roller, G. Giester, A. Rompel, Chem. Eur. J. 2015, 21, 4762 4771; d) Y. Wang, B. Li, H. Qian, L. Wu, Inorg. Chem. 2016, 55, 4271- 
4277; e) H. Karoui, C. Ritchie, Dalton Trans. 2016, 45, 18838-18841; f) T. Auvray, M.-P. Santoni, B. Hasenknopf, G. S. Hanan, Dalton Trans. 2017, 46, 10029-10036.

[17] S. Singh, K. Friedel, M. Himmerlich, Y. Lei, G. Schlinglo, A. Schober, ACS Macro Lett. 2015, 4, 1273-1277.

[18] N. Mallo, P. T. Brown, H. Iranmanesh, T. S. C. MacDonald, M. J. Teusner, J. B. Harper, G. E. Ball, J. E. Beves, Chem. Commun. 2016, 52, 1357613579.

[19] S. Bénard, P. Yu, Chem Commun. 2000, 65-66.

[20] M. M. Lerch, M. J. Hansen, W. A. Velema, W. Szymanski, B. L. Feringa, Nat. Commun., 2016, 7, 12054-12063.

[21] H. Mokbel, P. Xiao, C. Simonnet-Jégat, F. Dumur, D. Gigmes, J. Toufaily, T. Hamieh, J. P. Fouassier, J. Lalevée, J. Polym. Sci. Part A : Polym Chem. 2015, 53, 981-989.

[22] P. R. Marcoux, B. Hasenknopf, J. Vaissermann, P. Gouzerh, Eur. J. Inorg. Chem. 2003, 2406-2412.
[23] a) J.-P. Fouassier, J. Lalevée in Photoinitiators for Polymer Synthesis: Scope, Reactivity and Efficiency, Wiley-VCH Verlag GmbH, Weinheim, 2012; b) P. Sautrot-Ba, A. Contreras, S. Abbad Andaloussi, T. Coradin, C. Hélary, N. Razza, M. Sangermano, P.-E. Mazeran, J.-P. Malval, D.-L. Versace, J Mater. Chem. B 2017, 5, 7572-7582; c) L. Breloy, V. Brezová, J.-P. Malval, A. Rios de Anda, J. Bourgon, T. Kurogi, D. J. Mindiola, D.L. Versace, Macromolecules 2019, 52, 3716-3729.

[24] G. R. Buettner, Free Radic. Biol. Med., 1987, 3, 259-303.

[25] J. R. Hemmer, S. O. Poelma, N. Treat, Z. A. Page, N. D. Dolinski, Y. J. Diaz, W. Tomlinson, K. D. Clark, J. P. Hooper, C. Hawker, J. Read de Alaniz, J. Am. Chem. Soc. 2016, 138, 13960-13966. 


\section{FULL PAPER}

POMs and DASA: the first

compound associating in a single molecule a polyoxometalate and a reverse photochrome is reported. It can be activated via two orthogonal optical stimuli when ionically associated to an organic photochrome. Furthermore, its ability to act as a photoinitiator in free-radical polymerization process under visible light is demonstrated.

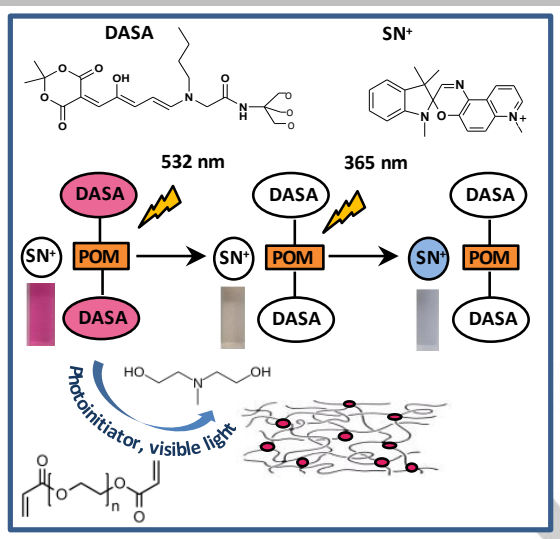

Amandine Boulmier, Mohamed Haouas, Somia Tomane, Anne Dolbecq, Anne Vallée, Vlasta Brezova, Davy-Louis Versace, Pierre Mialane and Olivier Oms

Page No. - Page No.

Photoactive Polyoxometalate/DASA covalent hybrids for photopolymerization in the visible range 